\title{
Overuse of inhaled corticosteroids in COPD: five questions for withdrawal in daily practice
}

This article was published in the following Dove Press journal:

International Journal of COPD

\section{Didier Cataldo' \\ Eric Derom ${ }^{2}$ \\ Giuseppe Liistro 3 \\ Eric Marchand ${ }^{4,5}$ \\ Vincent Ninane ${ }^{6}$ \\ Rudi Peché ${ }^{7}$ \\ Hans Slabbynck ${ }^{8}$ \\ Walter Vincken? \\ Wim Janssens ${ }^{10}$}

'Department of Respiratory Medicine, Centre Hospitalier Universitaire de Liège ( $\mathrm{CHU}$ ) and University of Liège, Liège, Belgium; '²Department of Respiratory Medicine, Ghent University Hospital, Gent, Belgium; ${ }^{3}$ Department of Respiratory Medicine, University Hospitals Saint-Luc, Brussels, Belgium; ${ }^{4}$ Department of Respiratory Medicine, University Hospital UCL Namur, Yvoir, Belgium; ${ }^{5}$ URPhyM, University of Namur, Namur, Belgium; ${ }^{6}$ Department of Respiratory Medicine, University Hospital Saint-Pierre, Université Libre de Bruxelles, Brussels, Belgium; ${ }^{7}$ Department of Respiratory Medicine, University Hospital Vésale, Montignyle-Tilleul, Belgium; ${ }^{8}$ Department of Respiratory Medicine, ZNA Middelheim, Antwerpen, Belgium; ${ }^{9}$ Respiratory Division, University Hospital Brussels (UZ Brussel), Vrije Universiteit Brussel, Brussels, Belgium; ${ }^{10}$ Department of Respiratory Medicine, University Hospitals Leuven, Leuven, Belgium

Correspondence: Didier Cataldo Department of Respiratory Medicine, Centre Hospitalier Universitaire de Liège, University of Liège, Hippocrates Avenue, 13 - Building B23, Third floor, 4000

Liège, Belgium

Tel +3243662521

Fax +32 43662939

Email didier.cataldo@uliege.be

\begin{abstract}
Evidence and guidelines are becoming increasingly clear about imbalance between the risks and benefits of inhaled corticosteroids (ICSs) in patients with COPD. While selected patients may benefit from ICS-containing regimens, ICSs are often inappropriately prescribed with - according to Belgian market research data - up to $70 \%$ of patients in current practice receiving ICSs, usually as a fixed combination with a long-acting $\beta_{2}$-adrenoreceptor agonist. Studies and recommendations support withdrawal of ICSs in a large group of patients with COPD. However, historical habits appear difficult to change even in the light of recent scientific evidence. We have built a collaborative educational platform with chest physicians and primary care physicians to increase awareness and provide guidance and support in this matter.
\end{abstract}

Keywords: COPD, exacerbation, withdrawal, inhaled steroids, systematic review, education

\section{Introduction}

Today, there is much debate on the appropriate prescription of inhaled corticosteroid (ICS) in patients with COPD. While there is a group of patients in whom the addition of ICS to a bronchodilator treatment may be beneficial, many patients are currently using it without a clear current indication. Our research aimed at summarizing scientific evidence available on the withdrawal of ICS in such patients and at discussing current gaps in the understanding in order to provide guidance to physicians, applicable in daily practice.

We searched the PubMed database for clinical trials, published in English language in the last 20 years, with the primary focus on efficacy/safety in patients with stable COPD, in whom ICS had been withdrawn from triple or dual bronchodilator treatment and who were compared to patients who continued on ICS. Information gaps were identified and discussed.

\section{Scientific rationale}

\section{How did we get this far?}

For many years now, the management of patients with COPD has been a matter of stepwise treatment escalation. ICSs and long-acting bronchodilators (long-acting $\beta_{2}$-adrenoreceptor agonists [LABAs] and long-acting muscarinic receptor antagonists [LAMAs]) are the three individual classes of inhaled medications used, alone or in combination, along the progressive course of the disease in order to reduce the burden in the individual patient.

Brusselle et al ${ }^{1}$ clearly illustrated in their analysis of the prescription patterns in the UK that this practice has routinely drifted patients into triple therapy. Actually, this happened in a progressive manner in most of the cases, regardless of the underlying disease severity or stage. ${ }^{1}$ Starting patients on a fixed combination of ICS/LABA was 
identified as the main driver toward triple treatment. ${ }^{1}$ In addition, primary care physicians often lack spirometry at baseline to help differentiate asthma from COPD. This might favor a treatment choice that covers both diagnoses.

These discrepancies between treatment recommendations and real-life use of ICS were found in surveys performed in many countries. ${ }^{2,3}$ Along the same lines, Belgian market research data confirm the disconnection between guidelines and prescription patterns with up to $70 \%$ of newly diagnosed patients with COPD receiving ICS-based treatment from the start (Cegedim database, second quarter 2015, unpublished data). Local reimbursement criteria (ie, LAMA and LABA/ LAMA must receive an a priori clearance from the Belgian health care system as opposed to LABA or LABA/ICS) have obviously played a part in the shaping and persistence of these treatment patterns.

So far, the overuse of ICS appears to be a product of history. In the 1990s, indeed, ICS was prescribed in patients with COPD by mere analogy with asthma treatment. ${ }^{4}$ The evidence base was brought ex post by the ISOLDE and later TORCH studies, which confirmed superiority of the ICS alone or in combination with LABA over placebo in terms of exacerbation prevention. ${ }^{5,6}$ UPLIFT then demonstrated that LAMA used on top of a LABA/ICS combination, which had become usual care at that time, induced an additional reduction in exacerbations. ${ }^{7}$ However, the INSPIRE study started to challenge the ICS supremacy as it showed no significant difference in exacerbation rates with salmeterol (SAL)/ fluticasone combination versus tiotropium monotherapy in patients with severe to very severe COPD and a history of exacerbations. ${ }^{8}$ The FLAME study later showed that double bronchodilation with LAMA/LABA was more effective in preventing exacerbations of COPD than the classical LABA/ ICS combination in a selected population of patients without an asthmatic component. ${ }^{9}$ While evidence is available that stepping up from ICS/LABA into triple therapy may be beneficial in COPD patients, ${ }^{10-12}$ it remains to be determined in which patients ICS may show additional benefit on top of a LABA/LAMA double bronchodilation. Very recently, the TRIBUTE study found that triple therapy with beclomethasone significantly reduced the rate of moderate-to-severe exacerbations compared to indacaterol/glycopyrronium dual bronchodilation in the upper group of COPD patients with severe or very severe airflow limitation and at least one moderate-to-severe exacerbation in the previous year. ${ }^{13}$ The IMPACT study, which compared triple therapy with fluticasone furoate/umeclidinium/vilanterol with its respective LAMA/LABA and LABA/ICS combinations, confirmed the statistically significant reduction in moderate-to-severe exacerbations and exacerbations leading to hospitalization in a COPD population at high risk for events. However, it was also confirmed that the addition of ICS to dual bronchodilation treatment increased the risk for pneumonia. ${ }^{14}$ It has to be further analyzed whether the inclusion of patients currently treated with ICS (and for some a possible history of asthma), associated with the abrupt withdrawal of ICS when patients were randomized in the LAMA/LABA group, may have contributed to the higher rate of exacerbations. ${ }^{14,15}$

\section{Making a U-turn}

In the meantime, the WISDOM study and previous trials with smaller cohorts breached the conservative step-up thinking with the introduction of de-escalation of ICS treatment in the management of COPD. ${ }^{16}$ The WISDOM study showed that LAMA/LABA double bronchodilator treatment is non-inferior to an LAMA plus LABA/ICS triple treatment in reducing the risk of moderate to severe exacerbations in patients with severe to very severe COPD. ${ }^{16}$ Post hoc analysis showed that ICS as part of a triple regimen provided an incremental exacerbation benefit in only a minority $(7 \%)$ and clearly identifiable subset of the WISDOM cohort. ${ }^{17}$ These were patients with severe to very severe COPD, a history of frequent exacerbations ( $\geq 2$ exacerbations/year), and a high blood eosinophil count ( $\geq 300$ cells $/ \mu \mathrm{L})$. In line with the WISDOM study, evidence is accumulating that certain COPD subtypes may differ in their responses to ICS. ${ }^{18-23}$

The 2017 report of the Global Initiative for Chronic Obstructive Lung Disease (GOLD) has integrated abovementioned evidence from the FLAME and WISDOM studies and proposed a stepwise approach to the overuse of ICS, with dose escalation and/or de-escalation strategies according to the individual patient symptoms and exacerbation risk (Box 1) ${ }^{24}$ There are growing concerns about the inappropriate prescribing and over-use of ICS and its potential negative health consequences..$^{25}$ Indeed, there is now strong evidence for increased incidence of pneumonia, along with other side effects, such as oropharyngeal candidiasis, hoarseness, and skin bruising. ${ }^{24,26}$ The evidence linking ICS use to decreased bone density and fractures, increased risk of diabetes, cataracts, and mycobacterial infection (eg, tuberculosis) is less strong. ${ }^{24}$ Interestingly, the risk of pneumonia associated with ICS use appears to be dose dependent. ${ }^{27}$ The severity of COPD might also be correlated to the risk of pneumonia. ${ }^{28}$

Since Suissa et $\mathrm{al}^{29}$ had demonstrated in their Quebec cohort of $>100,000$ COPD patients that the elevated incidence of severe pneumonia (2.8/100 patient-years) was reduced by $20 \%$ and $50 \%$ (in the first month and fourth month, respectively) after discontinuation of ICS, it is time 
Box I Role of ICS in COPD - GOLD 2017 recommendations

- ICS monotherapy is not recommended

- ICS-containing regimens are not recommended as initial maintenance treatment for COPD patients, except in some patients, such as in those with a history and/or findings suggestive of asthma-COPD overlap where it may be a first choice

- LABA/ICS may be an alternative to LAMA/LABA therapy in frequent exacerbators with few symptoms, but it is not preferred due to the risk of pneumonia (Group C)

- Symptomatic patients with a history of frequent exacerbations (Group D) can be raised to an ICS-containing triple treatment if their symptoms persist or if they have further exacerbations despite optimal bronchodilation

Notes: Data from GOLD. Global Strategy for the Diagnosis, Management, and Prevention of Chronic Obstructive Pulmonary Disease (2017 Report). Global Initiative for Chronic Obstructive Lung Disease, Inc.; 2017.24

Abbreviations: ICS, inhaled corticosteroid; GOLD, Global Initiative for Chronic Obstructive Lung Disease; LABA, long-acting $\beta 2$-adrenoreceptor agonist; LAMA, long-acting muscarinic receptor antagonist.

for a more targeted use of ICS therapy in patients in whom the benefit outweighs the risk.

\section{Back on track}

Considering the vast pool of patients with COPD, there is a large subset of patients with a suboptimal benefit/risk balance with regard to ICS treatment. It is therefore needed to identify the right candidates for ICS withdrawal, particularly in the group of COPD patients receiving high doses of ICS..$^{30}$ However, evidence for guidance is limited at the moment. Moreover, there is resistance among physicians and patients to modify a longstanding treatment schedule in seemingly stable patients. While stepping-down from ICS is accepted in asthma with its fluctuating symptom pattern, many barriers might render this treatment modulation more complex in COPD.

\section{Five questions from daily practice}

Regardless of the decision to continue or withdraw ICS, it is essential to stress the value of smoking cessation (level of evidence A), pulmonary rehabilitation (level of evidence A), and adequate management of potential comorbidities in the management of COPD. ${ }^{24}$ Obviously, vaccination against flu and pneumococcus is essential, particularly in symptomatic patients at risk for exacerbations. Inhaled therapies are only effective if used correctly, and the inhaler technique should also be optimized at all clinical encounters and particularly if patients are being switched from one therapy (device) to another.

\section{I.Which COPD patients should be treated with ICS?}

In patients with COPD, there is definitely a minority of patients in whom a clear indication for ICS therapy is established. These are the patients with a positive benefit/ risk balance for the use of ICS. Although this group may not be finally defined yet, it particularly includes the following two categories:

\section{Patients who suffer from COPD and asthma}

The treatment regimen of patients with a history and/or findings suggestive of asthma-COPD overlap should always consist of a combination of ICS and bronchodilator(s); only in these patients, LABA/ICS combination treatment is appropriate as initial treatment. However, this applies to an estimated $15 \%-20 \%$ of the COPD patients at most and cannot explain the current overuse of ICS in COPD patients. ${ }^{22,31}$ Individual criteria, such as acute broncho-reversibility, are not sufficient to make a co-diagnosis of asthma in a COPD patient. ${ }^{32}$ Although not validated, most authors propose a combination of different clinical and test criteria to suspect asthma-COPD overlap and to introduce ICS in the treatment. ${ }^{22,33,34}$

\section{Frequent exacerbators despite optimal bronchodilation}

According to the latest GOLD recommendations, frequent exacerbators who remain symptomatic despite optimal bronchodilation (group D) are candidates for ICS. ${ }^{24}$ In these patients, ICS can be added on top of an LAMA/LABA bronchodilator combination. The benefit of triple therapy versus double bronchodilation in this specific group is still a matter of debate because the relevant scientific evidence is not available yet.

Validated biomarkers would help us to select those patients who may benefit from ICS. Subanalyses of large randomized trials have demonstrated a positive effect of ICS on the exacerbation risk in patients with high blood eosinophil counts, with the largest responses in patients with the highest blood counts $; ;^{35}$ protective effect of double bronchodilation was most pronounced in patients with lower eosinophilia. ${ }^{36}$ However, as most of the analyses were post hoc and the only predefined analysis of the FLAME study could not demonstrate any signal for eosinophil counts, the debate on the role of high blood eosinophil counts in COPD patients is still ongoing. ${ }^{18,20,37}$ Other markers are under consideration as well..$^{38}$

\section{Which COPD patients should not be treated with ICS?}

The use of ICS is inappropriate if the risks outweigh the benefits. Based on current evidence, this is probably true for the following: 


\section{Patients who suffered from severe ICS-related side} effects

COPD patients who suffered from severe side effects, such as pneumonia, should no longer be treated with ICS or cautiously be treated with a low-dose ICS, if the indication for ICS treatment was justified. ${ }^{29}$ The attention of physicians should be raised on the possible similarity between clinical features of pneumonia and symptoms of COPD exacerbations. To differentiate pneumonia from acute exacerbations, the experts consider a chest X-ray to be mandatory.

\section{Newly diagnosed patients}

Patients with a new diagnosis of COPD should not be started on ICS-containing therapy. The exceptions to this rule are patients with obvious signs of an asthma component. However, physicians should know that there is only a small minority of patients with COPD and asthma overlap, immediately necessitating ICS treatment. As the diagnosis of asthma-COPD overlap often requires longitudinal follow-up, ${ }^{22}$ the introduction of ICS in these COPD patients can be postponed to the moment that - despite optimized bronchodilator therapy - symptom control is not achieved and an underlying asthma component is still suspected.

\section{Patients without an established indication for ICS prescription}

There is consensus that ICS does not bring benefit to COPD patients without any history of exacerbations. ${ }^{24,39}$ Withdrawal of inappropriately prescribed ICS in these subjects is strongly indicated and should be considered, in our opinion, on a case-by-case basis.

\section{In which patient can we probably consider stopping ICS?}

Many patients are receiving ICS without a clear indication (ie, off-label and/or outside the current recommendations). Moreover, doctors have often no insight into the reasons why ICS has been introduced in the past. In these patients, withdrawal of ICS should be considered. Usually, these patients were started on ICS prior to the introduction of the recent guidelines, irrespective of their exacerbation frequency, and without optimizing the concomitant bronchodilator medication. Additionally, LAMA/LABA combinations often did not exist at the time ICS/LABA was initiated and may prove equally effective in the risk reduction of exacerbations.

Today, there is consensus that, particularly in the nonfrequent exacerbators who are managed with an optimal bronchodilator treatment, ICS should be tapered and finally withdrawn without affecting the disease (Figure 1). ${ }^{16}$

\section{What is the evidence that supports an ICS withdrawal strategy?}

The current literature on ICS withdrawal is limited. Our systematic literature search retrieved eight comparative clinical trials that dealt with the withdrawal of ICS in patients with $\mathrm{COPD}^{16,40-46}$ and two meta-analyses. ${ }^{47,48}$ Table 1 shows the heterogeneity of these studies with regard to design (randomized, controlled, or observational) and provides an overview of the main study characteristics. Although GOLD recommendations have never advocated the use of ICS in patients with $\mathrm{FEV}_{1}>50 \%$, patient populations vary from mild to very severe COPD and include frequent and non-frequent exacerbators. We also found six interesting withdrawal studies that were excluded on closer look. These studies did not

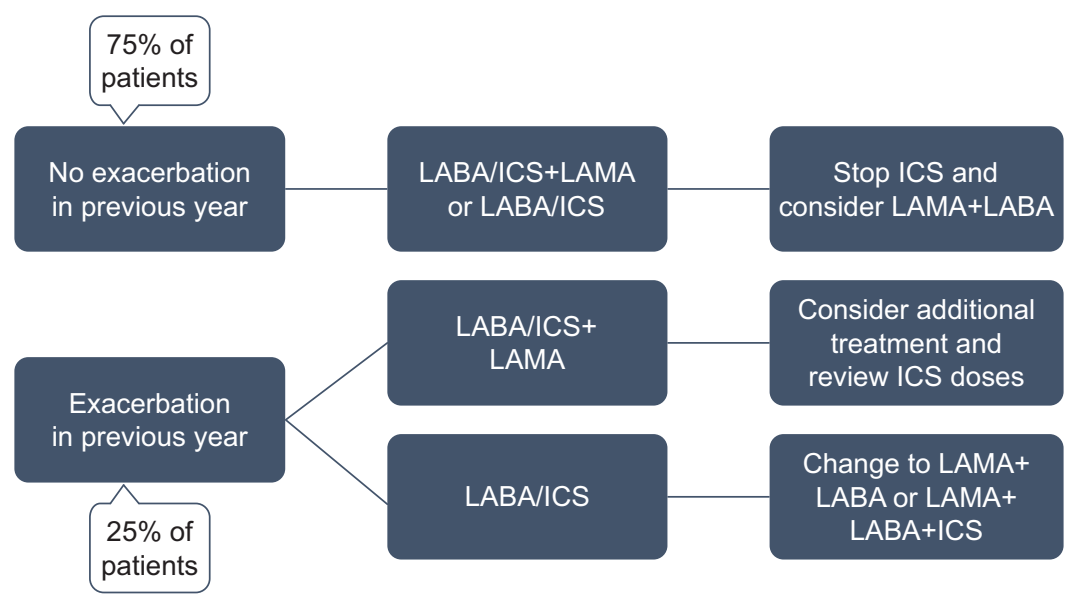

Figure I Algorithm for withdrawal of ICS in symptomatic patients with COPD. ${ }^{a}$

Note: alf asthma-COPD overlap, continue ICS therapy and monitor for potential ICS-related adverse events; percentages of patients are based on the DACCORD population. ${ }^{55}$

Abbreviations: ICS, inhaled corticosteroid; LABA, long-acting $\beta 2$-adrenoreceptor agonists; LAMA, long-acting muscarinic receptor antagonist. 


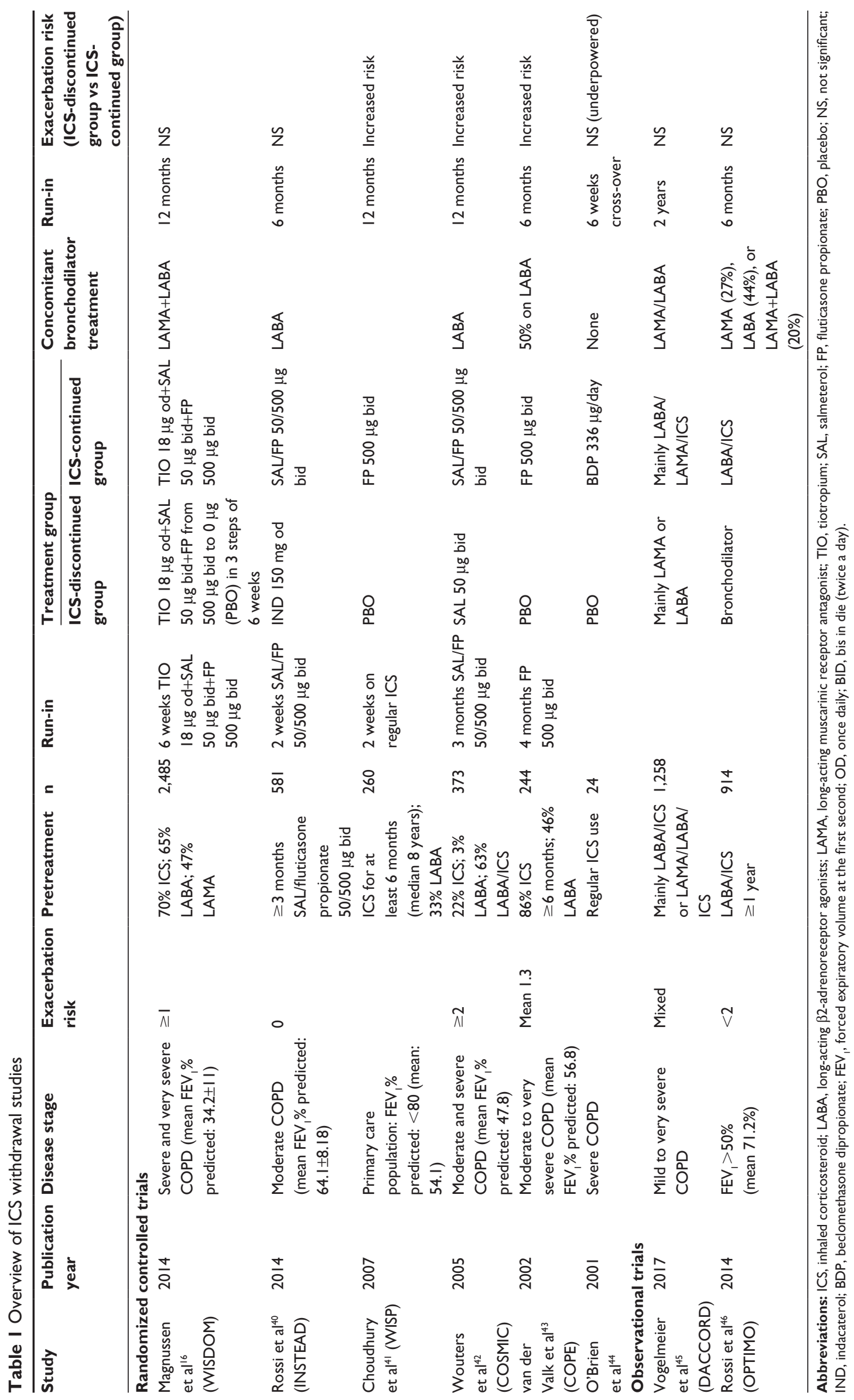


meet our criterion of having comparative ICS-continuation vs ICS-discontinuation treatment arms because all patients previously receiving ICS were discontinued, ${ }^{49-51}$ ICS was not completely discontinued, ${ }^{52}$ or the bronchodilator treatment was withdrawn as well. ${ }^{53,54}$

Chronologically, O'Brien et $\mathrm{al}^{44}$ were the first to describe ICS withdrawal in a small and underpowered group of elderly patients with severe airway obstruction, who were on regular ICS without a clear indication. They found a small decline in $\mathrm{FEV}_{1}$ during the ICS-free study interval compared to the ICS treatment interval (-6.28\% vs 5.03\%; 95\% CI: -23.28 to 0.76 ; not significant [NS]), and more patients experienced an exacerbation of COPD symptoms (3/18 vs 0/16 patients; NS). The authors mentioned that patients were using short-acting salbutamol and ipratropium at study entry, four patients were on theophylline, and two on home oxygen therapy. We assume that these treatments were continued during all cross-over intervals.

The COPE study had a mixed population of patients with moderate to very severe COPD. ${ }^{43}$ Most patients had been on ICS prior to study entry, and approximately half of patients were on concomitant LABA maintenance treatment. However, it was not reported if underlying LABA treatment was randomly distributed across treatment groups. The risk for a first exacerbation was significantly increased in the ICS-discontinuation group (hazard ratio [HR] 1.5; 95\% CI 1.1-2.1). Subgroup analysis found that this effect was predominant in the patients with low $\mathrm{FEV}_{1}$ (HR 2.1; 95\% CI 1.1-3.6), whereas no significant effect of ICS withdrawal was found in the subgroup of patients with better preserved ( $\geq 50 \%$ of predicted value) $\mathrm{FEV}_{1}$ (HR $1.2 ; 95 \%$ CI $0.8-2.0$ ). Altogether, $40 \%$ of the patients did not experience any untoward effect from ICS withdrawal.

Wouters et $\mathrm{al}^{42}$ reported the results of the COSMIC trial with patients at a high risk for exacerbations. Most patients were taking ICS before screening, and all were continuing LABA treatment (SAL $50 \mu \mathrm{g}$ bid) during the entire study period. No LAMA treatment was reported. One year after randomization, ICS withdrawal resulted in a decrease of $\mathrm{FEV}_{1}$, albeit small (50 mL; 95\% CI 0.01-0.10; $P=0.022$ ). ICS discontinuation also resulted in an increased rate of mild exacerbations (mean annual incidence rate: 1.3 vs 0.6 ; $P=0.020$ ) and a trend toward more moderate to severe exacerbations (adjusted rate ratio: 1.2; 95\% CI 0.9-1.5; NS).

Similarly, in the primary care population of the WISP trial, ${ }^{41}$ ICS discontinuation increased the risk for exacerbations (relative risk [RR]: 1.48; 95\% CI 1.17-1.86). The WISP trial consisted of patients on long-term ICS treatment and $\sim 30 \%$ of patients on concomitant LABA. The authors reported that these LABA users were mainly found in the more severe subgroup $\left(\mathrm{FEV}_{1} \leq 50 \%\right.$ or at least two courses of antibiotics/oral steroids in the previous year). ICS discontinuation resulted in a non-significant increase in the rate of exacerbations in this subgroup (RR 1.24; 95\% CI 0.96-1.41; NS). Inversely, in the mild COPD group, significantly more exacerbations occurred upon withdrawal of ICS as compared to those in the ICScontinuation group (RR 1.94; 95\% CI 1.20-3.14). No information is available on the protective treatment given in the mild group. One may assume that after ICS withdrawal, these patients were maintained with short-acting rescue medication.

Meta-analysis of above-mentioned trials by Nadeem et $\mathrm{al}^{47}$ found no statistical confirmation that withdrawing ICS in routine practice would result in important deterioration of patient outcomes and attributed this mainly to the differences in definitions, outcomes, and management.

More recently, the INSTEAD trial demonstrated that ICS can be safely withdrawn from a fixed ICS/LABA combination in a population with moderate $\mathrm{COPD}\left(\mathrm{FEV}_{1} 50 \%-80 \%\right.$ predicted). ${ }^{40}$ There was neither increase in exacerbation risk (time to first moderate or severe exacerbation: HR 0.80; $P=0.258)$ nor worsening of lung function $\left(\mathrm{FEV}_{1}\right.$ change of $9 \mathrm{~mL}$ at 12 weeks; $95 \% \mathrm{CI}-45$ to 26 ; non-inferior). The protective effect of the LABA bronchodilator turned out to be sufficient in this group.

The WISDOM study then showed that ICS doses can also be gradually decreased and withdrawn in patients with severe to very severe COPD who are on triple therapy. ${ }^{16}$ There was neither clinically significant deterioration in patient-reported outcomes nor statistically significant increase in exacerbation rates. ICS withdrawal induced a statistically significant loss in trough $\mathrm{FEV}_{1}$ of $\sim 40 \mathrm{~mL}$ that was not considered clinically relevant and was stable over time. As mentioned earlier, post hoc analysis found that long-term ICS treatment may reduce the rate of exacerbations in a selected subgroup of patients with blood eosinophil counts of $>300$ cells $/ \mu \mathrm{L} .^{18}$

A very recent meta-analysis of Calzetta et $\mathrm{al}^{48}$ confirmed that ICS withdrawal did not significantly $(P>0.05)$ increase the overall rate of COPD exacerbations; however, the analysis detected an increased risk of severe exacerbations ( RR >1.2).

From our systematic review of ICS withdrawal studies, we conclude that optimal bronchodilator treatment is an essential condition for successful withdrawal of ICS treatment. Unfortunately, many of the older studies did not clearly state which - if any - underlying maintenance treatments 


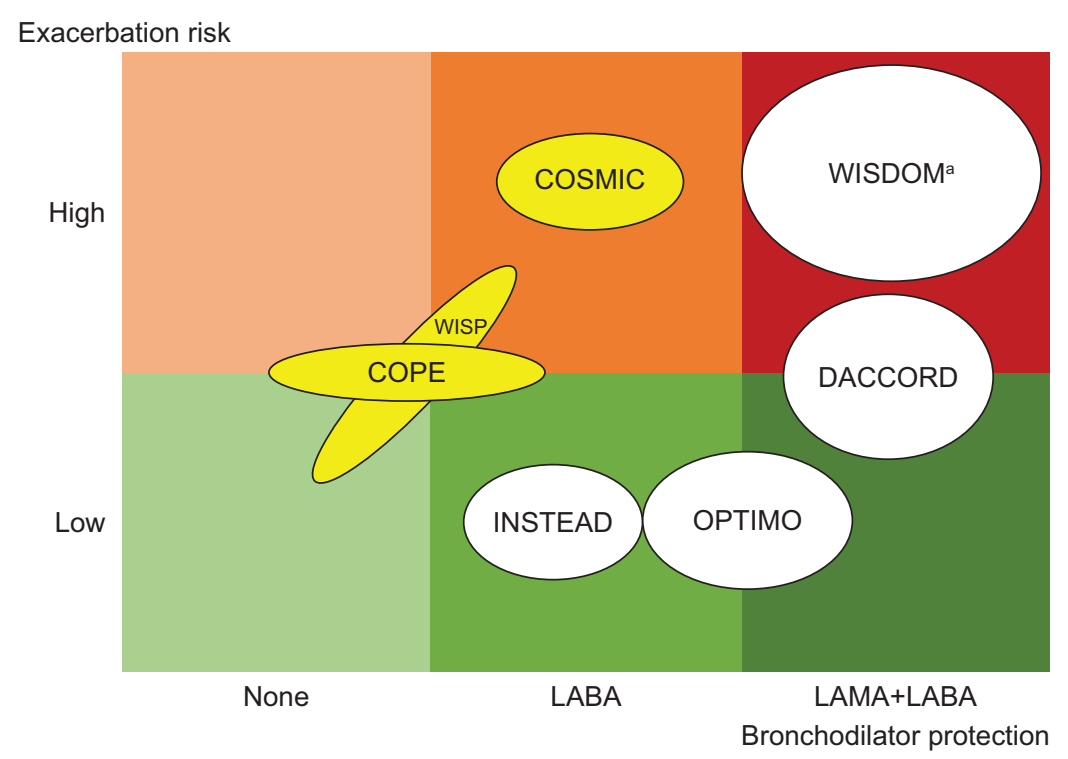

Figure 2 Simplified model for bronchodilator protection, based on ICS withdrawal studies (Table I).

Notes: The relative size of the ellipses corresponds with the number of patients in each study. White ellipse indicates that the exacerbation rate is similar in ICS-discontinued and ICS-continued groups. Yellow ellipse indicates that the exacerbation rate is higher in the ICS-discontinued group than in the ICS-continued group. aCS may be beneficial in a well-defined subpopulation.

Abbreviations: ICS, inhaled corticosteroid; LABA, long-acting $\beta 2$-adrenoreceptor agonists; LAMA, long-acting muscarinic receptor antagonist.

were used. Future withdrawal studies should at least take these weaknesses into account. Figure 2 shows a hypothetical model of the risk associated with ICS withdrawal, as a direct relationship between the patient risk for exacerbation and the level of protective bronchodilator treatment provided. As in the WISDOM trial, many patients can be safely withdrawn from ICS, even patients with severe to very severe COPD, if a double LAMA+LABA protection is provided. The INSTEAD trial illustrated in a low-risk group that even mono-bronchodilation may be sufficient to allow for ICS withdrawal, whereas the COSMIC study showed that it was not enough to avoid exacerbations when withdrawing ICS in a patient group at high risk for exacerbations.

The two large real-life studies with randomized and prospective design, OPTIMO and DACCORD, confirmed that ICS can be withdrawn without increased risk of exacerbations, provided appropriate bronchodilator treatment is initiated. ${ }^{45,46}$ In these studies, the decision to withdraw the ICS was left at the investigators' discretion. Therefore, these studies demonstrate that treating physicians have the required skills to select the right patients for ICS withdrawal. LABA/ LAMA combinations are used to optimize bronchodilation and allow for more convenient ICS withdrawal.

\section{How should we withdraw patients from ICS?}

Currently, there is no best practice guidance available for ICS withdrawal. The withdrawal studies do not provide further information, as - except in the WISDOM trial - ICS has been stopped abruptly.

In medical practice, data are lacking to help decide whether stopping long-term corticosteroid treatment abruptly is recommended. There are scarce indications that patients might be put at risk for systemic rebound effects as shown when patients were weaned from steroids in the run-in period of the ISOLDE study. ${ }^{49}$ On the other hand, outside the controlled-trial setting, nonadherence to treatment is common and many patients are not taking ICS as prescribed. ${ }^{52}$

The WISDOM study provides a clear de-escalation schedule that isolates the ICS component from the triple treatment and then gradually reduces the ICS dose (Figure 3). Since there is no established guidance on the withdrawal method to be used, we suggest tapering the dose in case of any doubt. Optimizing bronchodilation should probably be considered when withdrawing the ICS component (Figure 3).

\section{How can we potentially overcome barriers to step down from ICS?}

Since there is no established guidance on the withdrawal method to be used, we suggest tapering the dose in case of any doubt. The ICS component is uncoupled from the triple treatment in order to reduce the dose gradually, ie, reduce the ICS strength and/or the number of inhalations per day. The risk that unlicensed single ICS formulations are used to achieve this dose tapering should be considered. To avoid 


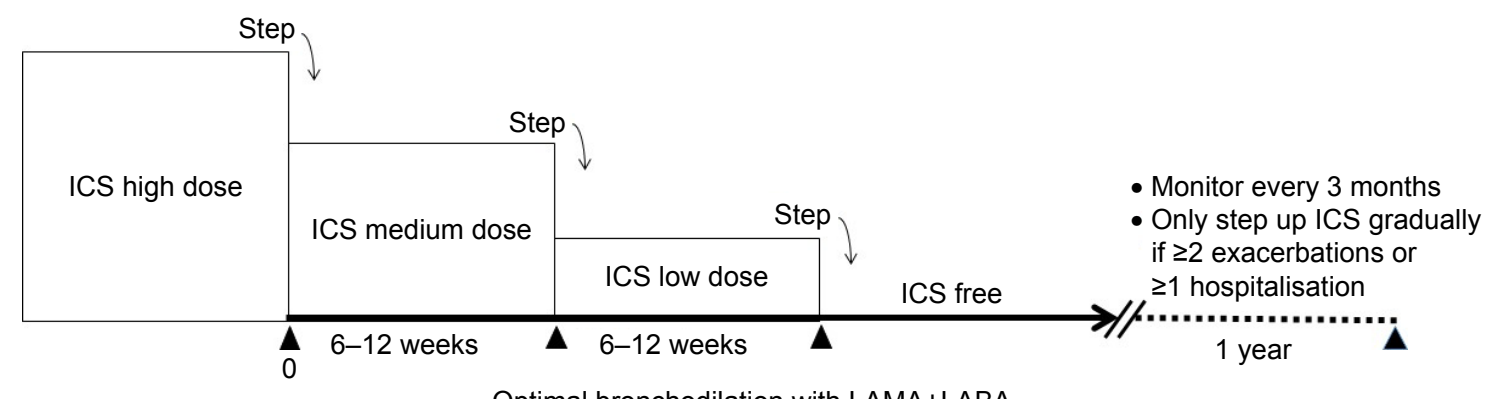

Optimal bronchodilation with LAMA+LABA

Figure 3 De-escalation of ICS, according to WISDOM. ${ }^{56}$

Abbreviations: ICS, inhaled corticosteroid; LAMA, long-acting muscarinic receptor antagonist; LABA, long-acting $\beta 2$-adrenoreceptor agonists.

confusing the patient, it is also advised to keep the number of switches between inhaler types as low as possible.

Importantly, patients must be carefully counseled on the potential benefit of the intervention. Taking away part of a long-term treatment is known to cause a nocebo effect. Therefore, if possible, the number of inhalers should remain constant while reducing the ICS component.

There are arguments to review patients during the withdrawal (eg, every 3-6 months), but patients and physicians must be aware that the benefits of ICS withdrawal are expected in the long run. Switching back should only be considered if there is an important medical need. An important loss of $\mathrm{FEV}_{1}$ measured at several follow-up visits, repeated exacerbations and persistent symptom increase, may be considered to accept ICS introduction.

\section{Educational matters}

From our personal experience, we conclude that organizing small focus groups with the primary care physicians of our own network is the best way to approach ICS-withdrawal issues. Very importantly, the general practitioners need to understand why pulmonologists have withdrawn ICS from their patient's treatment scheme. In addition, they require sufficient insights and support to explain the treatment adjustment to their patients and help them adhere to the new treatment scheme.

Moreover, they will learn how to identify patients for ICS reduction or withdrawal themselves.

In our collaborative meeting concept, physicians bring their own anonymized patient cases for exploration. Scientific information, as described earlier, is delivered in a highly interactive manner. Post-meeting testing and follow-up are foreseen.

\section{Action points for ICS withdrawal}

This section provides some general recommendations from our panel.

\section{Action points for treating physicians}

Physicians should reconsider the usefulness of ICS use according to the 2017 GOLD report and in a personalized medicine perspective. In patients without an established indication for ICS, stepping down could be considered. Primary care physicians and specialists must be aligned in providing extensive patient education.

\section{Action points for professional organizations and educators}

More efforts are required to increase awareness on potential risks of ICS overprescription. Educational programs may help physicians to select the right candidates for ICS withdrawal and to combat ICS prescription driven by fear, habit, confusion about asthma-COPD overlap, or the lack of information on de-escalating ICS therapy. Patient monitoring after ICS withdrawal requires a well-organized collaboration between primary care and secondary care. Monitoring projects and patient registries and perhaps integrated care may help to improve outcomes. Fast dissemination of knowledge and practice recommendations among medical practitioners must be aimed for.

\section{Action points for health authorities and pharmaceutical companies}

Medication access and reimbursement should be aligned with current treatment recommendations.

Although ICS monotherapy is not indicated in COPD, appropriate formulations must be made available to isolate the ICS component from combination treatments and gradually reduce the dose. Close collaboration between secondary care and primary care should be promoted to facilitate early patient assessment and development of an individual treatment plan. Integrated care initiatives, such as e-health developed by the authorities in Belgium, may involve primary care physicians, pharmacists, and chest physicians to improve patient monitoring and achieve common goals. 


\section{Conclusion}

There is a large group of patients in whom ICS can be withdrawn without any untoward effects. The time is now to identify these patients and manage them appropriately. Changing historical prescription habits is difficult, but it may prove valuable in the future.

\section{Acknowledgments}

Boehringer Ingelheim Belgium has organized and funded the round table discussions but had no input in development of this manuscript. The authors received no compensation related to the development of the manuscript. Medical writing assistance was provided by Hedwig Stals of HD Consultancy and was also funded by Boehringer Ingelheim.

\section{Author contributions}

All authors have substantially contributed to the concept of this research and the drafting and critical revision of the manuscript, agree to be accountable for all aspects of the work, and have approved the final version.

\section{Disclosure}

DC is the founder of Aquilon Pharmaceuticals and had received speaker fees from AstraZeneca, Boehringer Ingelheim, Novartis, Mundipharma, Chiesi, and GlaxoSmithKline (GSK) and consultancy fees from AstraZeneca, Boehringer Ingelheim, Chiesi, GSK and Novartis for the participation to advisory boards. ED's clinical department received financial support from Boehringer Ingelheim and Novartis to perform clinical studies. He participated in advisory boards by Boehringer Ingelheim, Chiesi, Cipla, Novartis, and AstraZeneca, for which a fee was given to the clinical department. He received travel grants from Boehringer Ingelheim, GSK, and AstraZeneca to attend international congresses. He also received speaker fees from Boehringer Ingelheim, GSK, AstraZeneca, and Novartis to give scientific presentations to local GP groupings for which a fee was given to the clinical department. GL received speaker fees from Boehringer Ingelheim, Novartis, and Chiesi and consultancy fees from AstraZeneca, Boehringer Ingelheim, Chiesi, and Novartis for the participation to advisory boards. EM received speaker fees from AstraZeneca, Boehringer Ingelheim, Chiesi, and Novartis and consultancy fees from AstraZeneca, Boehringer Ingelheim, Chiesi, GSK, and Novartis for the participation to advisory boards. VN received speaker fees from AstraZeneca, Boehringer Ingelheim, Novartis, and Bristol-Myers Squibb and consultancy fees from AstraZeneca, Boehringer Ingelheim, Novartis, Bristol-Myers Squibb, and GSK for the participation to advisory boards. RP received speaker fees from AstraZeneca, Boehringer Ingelheim, Novartis, Chiesi, and GSK and consultancy fees from AstraZeneca, Boehringer Ingelheim, Chiesi, GSK, and Novartis for the participation to advisory boards. HS received speaker fees from AstraZeneca, Boehringer Ingelheim, and Roche and consultancy fees from Boehringer Ingelheim, GSK, and Roche for the participation to advisory boards. WV has been a member of advisory boards of and/or has been a speaker for AstraZeneca, Boehringer Ingelheim, Chiesi, GSK, and Novartis. WJ is a senior clinical researcher of the FWO. He is a chair holder of the Belgian AstraZeneca Chair for Respiratory Pathophysiology. He received research grants and consultancy fees from Boehringer Ingelheim, AstraZeneca, Novartis, Chiesi, and GSK. The authors report no other conflicts of interest in this work.

\section{References}

1. Brusselle G, Price D, Gruffydd-Jones K, et al. The inevitable drift to triple therapy in COPD: an analysis of prescribing pathways in the UK. Int J Chron Obstruct Pulmon Dis. 2015;10:2207-2217.

2. Jochmann A, Neubauer F, Miedinger D, Schafroth S, Tamm M, Leuppi JD. General practitioner's adherence to the COPD GOLD guidelines: baseline data of the Swiss COPD Cohort Study. Swiss Med Wkly. Epub 2010 Apr 21.

3. Lucas AE, Smeenk FW, Smeele IJ, van Schayck CP. Overtreatment with inhaled corticosteroids and diagnostic problems in primary care patients, an exploratory study. Fam Pract. 2008;25(2):86-91.

4. Kaplan AG. Applying the wisdom of stepping down inhaled corticosteroids in patients with COPD: a proposed algorithm for clinical practice. Int J Chron Obstruct Pulmon Dis. 2015;10:2535-2548.

5. Calverley P, Pauwels R, Vestbo J, et al. Combined salmeterol and fluticasone in the treatment of chronic obstructive pulmonary disease: a randomised controlled trial. Lancet. 2003;361(9356):449-456.

6. Calverley PM, Anderson JA, Celli B, et al. Salmeterol and fluticasone propionate and survival in chronic obstructive pulmonary disease. N Engl J Med. 2007;356(8):775-789.

7. Tashkin DP, Celli B, Senn S, et al. A 4-year trial of tiotropium in chronic obstructive pulmonary disease. $N$ Engl J Med. 2008; 359(15):1543-1554

8. Wedzicha JA, Calverley PM, Seemungal TA, et al. The prevention of chronic obstructive pulmonary disease exacerbations by salmeterol/ fluticasone propionate or tiotropium bromide. Am J Respir Crit Care Med. 2008;177(1):19-26.

9. Wedzicha JA, Banerji D, Chapman KR, et al. Indacaterol-glycopyrronium versus salmeterol-fluticasone for COPD. N Engl J Med. 2016;374(23): 2222-2234.

10. Singh D, Papi A, Corradi M, et al. Single inhaler triple therapy versus inhaled corticosteroid plus long-acting beta2-agonist therapy for chronic obstructive pulmonary disease (TRILOGY): a double-blind, parallel group, randomised controlled trial. Lancet. 2016;388(10048): 963-973.

11. Lipson DA, Barnacle H, Birk R, et al. FULFIL trial: once-daily triple therapy for patients with chronic obstructive pulmonary disease. Am J Respir Crit Care Med. 2017;196(4):438-446.

12. Tashkin DP, Taube C. Triple therapy for chronic obstructive pulmonary disease management. Are our expectations fulfilled? Am J Respir Crit Care Med. 2017;196(4):402-404.

13. Papi A, Vestbo J, Fabbri L, et al. Extrafine inhaled triple therapy versus dual bronchodilator therapy in chronic obstructive pulmonary disease (TRIBUTE): a double-blind, parallel group, randomised controlled trial. Lancet. 2018;391(10125):1076-1084. 
14. Lipson DA, Barnhart F, Brealey N, et al. Once-daily single-inhaler triple versus dual therapy in patients with COPD. N Engl J Med. 2018; 378(18):1671-1680.

15. Suissa S, Drazen JM. Making sense of triple inhaled therapy for COPD N Engl J Med. 2018;378(18):1723-1724.

16. Magnussen H, Disse B, Rodriguez-Roisin R, et al. Withdrawal of inhaled glucocorticoids and exacerbations of COPD. $N$ Engl J Med. 2014;371(14):1285-1294.

17. Calverley PM, Tetzlaff K, Vogelmeier C, et al. Eosinophilia, frequent exacerbations, and steroid response in chronic obstructive pulmonary disease. Am J Respir Crit Care Med. 2017;196(9):1219-1221.

18. Watz H, Tetzlaff K, Wouters EF, et al. Blood eosinophil count and exacerbations in severe chronic obstructive pulmonary disease after withdrawal of inhaled corticosteroids: a post-hoc analysis of the WISDOM trial. Lancet Respir Med. 2016;4(5):390-398.

19. Pascoe S, Locantore N, Dransfield MT, Barnes NC, Pavord ID. Blood eosinophil counts, exacerbations, and response to the addition of inhaled fluticasone furoate to vilanterol in patients with chronic obstructive pulmonary disease: a secondary analysis of data from two parallel randomised controlled trials. Lancet Respir Med. 2015;3(6):435-442.

20. Pavord ID, Lettis S, Locantore N, et al. Blood eosinophils and inhaled corticosteroid/long-acting beta-2 agonist efficacy in COPD. Thorax. 2016;71(2):118-125.

21. Siddiqui SH, Guasconi A, Vestbo J, et al. Blood eosinophils: a biomarker of response to extrafine beclomethasone/formoterol in chronic obstructive pulmonary disease. Am J Respir Crit Care Med. 2015; 192(4):523-525.

22. Cataldo D, Corhay JL, Derom E, et al. A Belgian survey on the diagnosis of asthma-COPD overlap syndrome. Int J Chron Obstruct Pulmon Dis. 2017;12:601-613.

23. Vestbo J, Papi A, Corradi M, et al. Single inhaler extrafine triple therapy versus long-acting muscarinic antagonist therapy for chronic obstructive pulmonary disease (TRINITY): a double-blind, parallel group, randomised controlled trial. Lancet. 2017;389(10082):1919-1929.

24. GOLD. Global Strategy for the Diagnosis, Management, and Prevention of Chronic Obstructive Pulmonary Disease (2017 Report). Global Initiative for Chronic Obstructive Lung Disease, Inc.; 2017.

25. White P, Thornton H, Pinnock H, Georgopoulou S, Booth HP. Overtreatment of COPD with inhaled corticosteroids - implications for safety and costs: cross-sectional observational study. PLoS One. 2013;8(10):e75221.

26. Yang IA, Clarke MS, Sim EH, et al. Inhaled corticosteroids for stable chronic obstructive pulmonary disease. Cochrane Database Syst Rev. 2012;(7):CD002991.

27. European Medicines Agency. Pharmacovigilance Risk Assessment Committee (PRAC): inhaled corticosteroids (ICS) containing medicinal products indicated in the treatment of chronic obstructive pulmonary disease (COPD). Assessment Report EMA/330021/2016. 2016.

28. Vestbo J, Anderson JA, Brook RD, et al. Fluticasone furoate and vilanterol and survival in chronic obstructive pulmonary disease with heightened cardiovascular risk (SUMMIT): a double-blind randomised controlled trial. Lancet. 2016;387(10030):1817-1826.

29. Suissa S, Coulombe J, Ernst P. Discontinuation of inhaled corticosteroids in COPD and the risk reduction of pneumonia. Chest. 2015;148(5):1177-1183.

30. Miravitlles M, Cosio BG, Arnedillo A, et al. A proposal for the withdrawal of inhaled corticosteroids in the clinical practice of chronic obstructive pulmonary disease. Respir Res. 2017;18(1):198.

31. Barrecheguren M, Esquinas C, Miravitlles M. The asthma-chronic obstructive pulmonary disease overlap syndrome (ACOS): opportunities and challenges. Curr Opin Pulm Med. 2015;21(1):74-79.

32. Kesten S, Rebuck AS. Is the short-term response to inhaled betaadrenergic agonist sensitive or specific for distinguishing between asthma and COPD? Chest. 1994;105(4):1042-1045.

33. Miravitlles M, Soler-Cataluna JJ, Calle M, et al. A new approach to grading and treating COPD based on clinical phenotypes: summary of the Spanish COPD guidelines (GesEPOC). Prim Care Respir J. 2013;22(1):117-121.
34. Global Initiative for Asthma. Diagnosis of Diseases of Chronic Airflow Limitation: Asthma, COPD and Asthma-COPD Overlap Syndrome (ACOS). A Joint Project of GINA and GOLD. 2015. Available from: http://ginasthma.org/asthma-copd-and-asthma-copd-overlap-syndrome$\operatorname{acos} /$.

35. Bafadhel M, Pavord ID, Russell REK. Eosinophils in COPD: just another biomarker? Lancet Respir Med. 2017;5(9):747-759.

36. Papi A, Kostikas K, Wedzicha JA, et al. Dual bronchodilation response by exacerbation history and eosinophilia in the FLAME study. Am J Respir Crit Care Med. 2018;197(9):1223-1226.

37. Roche N, Chapman KR, Vogelmeier CF, et al. Blood eosinophils and response to maintenance chronic obstructive pulmonary disease treatment. Data from the FLAME Trial. Am J Respir Crit Care Med. 2017;195(9):1189-1197.

38. Grunig G, Baghdassarian A, Park SH, et al. Challenges and current efforts in the development of biomarkers for chronic inflammatory and remodeling conditions of the lungs. Biomark Insights. 2015;10(Suppl 4): $59-72$.

39. Nannini LJ, Lasserson TJ, Poole P. Combined corticosteroid and longacting beta(2)-agonist in one inhaler versus long-acting beta(2)-agonists for chronic obstructive pulmonary disease. Cochrane Database Syst Rev. 2012;(9):CD006829.

40. Rossi A, van der Molen T, del Olmo R, et al. INSTEAD: a randomised switch trial of indacaterol versus salmeterol/fluticasone in moderate COPD. Eur Respir J. 2014;44(6):1548-1556.

41. Choudhury AB, Dawson CM, Kilvington HE, et al. Withdrawal of inhaled corticosteroids in people with COPD in primary care: a randomised controlled trial. Respir Res. 2007;8:93.

42. Wouters EF, Postma DS, Fokkens B, et al. Withdrawal of fluticasone propionate from combined salmeterol/fluticasone treatment in patients with COPD causes immediate and sustained disease deterioration: a randomised controlled trial. Thorax. 2005;60(6):480-487.

43. van der Valk P, Monninkhof E, van der Palen J, Zielhuis G, van Herwaarden C. Effect of discontinuation of inhaled corticosteroids in patients with chronic obstructive pulmonary disease: the COPE study. Am J Respir Crit Care Med. 2002;166(10):1358-1363.

44. O'Brien A, Russo-Magno P, Karki A, et al. Effects of withdrawal of inhaled steroids in men with severe irreversible airflow obstruction. Am J Respir Crit Care Med. 2001;164(3):365-371.

45. Vogelmeier C, Worth H, Buhl R, et al. "Real-life" inhaled corticosteroid withdrawal in COPD: a subgroup analysis of DACCORD. Int J Chron Obstruct Pulmon Dis. 2017;12:487-494.

46. Rossi A, Guerriero M, Corrado A; OPTIMO/AIPO Study Group. Withdrawal of inhaled corticosteroids can be safe in COPD patients at low risk of exacerbation: a real-life study on the appropriateness of treatment in moderate COPD patients (OPTIMO). Respir Res. 2014;15:77.

47. Nadeem NJ, Taylor SJ, Eldridge SM. Withdrawal of inhaled corticosteroids in individuals with COPD - a systematic review and comment on trial methodology. Respir Res. 2011;12:107.

48. Calzetta L, Matera MG, Braido F, et al. Withdrawal of inhaled corticosteroids in COPD: a meta-analysis. Pulm Pharmacol Ther. 2017;45: $148-158$.

49. Jarad NA, Wedzicha JA, Burge PS, Calverley PM. An observational study of inhaled corticosteroid withdrawal in stable chronic obstructive pulmonary disease. ISOLDE Study Group. Respir Med. 1999;93(3):161-166.

50. Schermer TR, Hendriks AJ, Chavannes NH, et al. Probability and determinants of relapse after discontinuation of inhaled corticosteroids in patients with COPD treated in general practice. Prim Care Respir J. 2004;13(1):48-55.

51. Al-Kassimi FA, Alhamad EH, Al-Hajjaj MS, et al. Abrupt withdrawal of inhaled corticosteroids does not result in spirometric deterioration in chronic obstructive pulmonary disease: effect of phenotyping? Ann Thorac Med. 2012;7(4):238-242.

52. Kunz LIZ, Postma DS, Klooster K, et al. Relapse in FEV , decline after steroid withdrawal in COPD. Chest. 2015;148(2):389-396.

53. Borrill Z, Roy K, Kolsum U, et al. Seretide withdrawal increases airway inflammation in moderate COPD patients. Eur J Clin Pharmacol. 2009;65(11):1165-1166. 
54. Kim SA, Lee JH, Kim EK, et al. Outcome of inhaler withdrawal in patients receiving triple therapy for COPD. Tuberc Respir Dis (Seoul). 2016;79(1):22-30.

55. Kardos P, Vogelmeier C, Worth H, et al. A two-year evaluation of the 'real life' impact of COPD on patients in Germany: the DACCORD observational study. Respir Med. 2017;124:57-64.
56. Magnussen H, Watz H, Kirsten A, et al. Stepwise withdrawal of inhaled corticosteroids in COPD patients receiving dual bronchodilation: WISDOM study design and rationale. Respir Med. 2014;108(4): 593-599.

International Journal of COPD

\section{Publish your work in this journal}

The International Journal of COPD is an international, peer-reviewed journal of therapeutics and pharmacology focusing on concise rapid reporting of clinical studies and reviews in COPD. Special focus is given to the pathophysiological processes underlying the disease, intervention programs, patient focused education, and self management protocols.
Dovepress

This journal is indexed on PubMed Central, MedLine and CAS. The manuscript management system is completely online and includes a very quick and fair peer-review system, which is all easy to use. Visit http://www.dovepress.com/testimonials.php to read real quotes from published authors.

Submit your manuscript here: http://www.dovepress.com/international-journal-of-chronic-obstructive-pulmonary-disease-journal 